\title{
EXAME NEUROLÓGICO EM CRIANÇAS
}

\author{
NEUROLOGIC EXAMINATION IN CHILDREN
}

Carolina A.R. Funayama

Docente do Departamento de Neurologia, Psiquiatria e Psicologia Médica da Faculdade de Medicina de Ribeirão Preto da Universidade de São Paulo.

Correspondência: Profa.Dra. Carolina A. R. Funayama - Departamento de Neurologia, Psiquiatria e Psicologia Médica da Faculdade de Medicina de Ribeirão Preto - CEP: 14048-900 - Ribeirão Preto - FAX (016) 633-0866. E. Mail - carfunay@fmrp.usp.br

FUNAYAMA CAR. Exame neurológico em crianças. Medicina, Ribeirão Preto, 29: 32-43, jan./mar. 1996

RESUMO: Técnicas de exame neurológico em crianças, desde o período neonatal, são descritas, bem como modificações que ocorrem, no decorrer da maturação tono, reflexos, postura, coordenação, equilíbrio, linguagem, praxias e gnosias. Ao final, é apresentado um esquema que reúne dados da semiologia neurológica e do desenvolvimento até 7 anos.

UNITERMOS: Desenvolvimento Infantil. Recém- Nascido. Exame Neurológico. Criança.

Quanto mais avança a tecnologia para fins diagnósticos em medicina, mais se deve aprofundar no conhecimento da semiologia clínica, para que a indicação dos exames seja precisa, o tempo para se estabelecer o diagnóstico, mais curto, a prescrição terapêutica mais rápida e que se torne menos onerosa para o paciente. A semiologia clínica neurológica na criança é complexa, por suas modificações ao longo do desenvolvimento; busca sinais de lesões, localizatórios, ao mesmo tempo em que é rica na identificação das aquisições sensitivas, motoras, sensoriais e cognitivas. $\mathrm{Na}$ literatura, há publicações separadas de escalas de desenvolvimento e de exame neurológico nas diversas faixas etárias. O nosso objetivo é unir em um só protocolo dados destas avaliações, de modo a permitir ao médico uma apreciação do perfil neurológico e outros itens do desenvolvimento, ao mesmo tempo abrangente e que possa ser concluída em uma única consulta.

Elementos da semiologia neurológica normal do recém-nascido $(\mathrm{RN})$ e lactente têm sido descritos desde o início deste século, como os reflexos, por Magnus e De Kleijn em 1912 ${ }^{1}$, Moro, $1918^{2}$ e Landau, $1923^{3}$.
Entretanto, após 1950 é que esta semiologia vem sendo aprimorada e, hoje, está padronizada, por valiosas contribuições como as de André Thomas e Dargassies, $1952^{4}$ na França; Illingworth, $1960^{5}$ e Sheridan, $1968^{6}$ na Inglaterra; Prechtl, $1964^{7}$ na Holanda; Brandt, $1986^{8}$ na Alemanha; Dubowitz, $1970^{9}$ nos Estados Unidos; Coriat, $1960^{10}$ na Argentina, entre outros. No Brasil, destacaram-se os Profs. Antônio Branco Lefèvre, $1950^{11}$ e Aron Diament, $1967^{12}$, que, avaliando crianças da cidade de São Paulo, aperfeiçoaram técnicas antigas e propuseram novas. Além da padronização do exame neurológico no RN, Lefèvre, $1972^{13}$ descreveu o exame neurológico evolutivo do terceiro ao sétimo ano de vida. Mais recentemente, o estudo da semiologia das funções corticais superiores e suas conexões (praxias, gnosias, linguagem, atenção-memória-evocação) tem sido um desafio no contexto dos processos maturativos. Há que se levar em conta aspectos da plasticidade funcional ao longo da maturação e, ainda, o conhecimento dos estágios do desenvolvimento da aprendizagem. Em esforço conjunto de especialistas afins, testes para 
avaliação das funções corticais para crianças têm sido propostos, no Brasil, a partir de $1989^{14,15}$.

Para obtermos um exame satisfatório, é aconselhável que o ambiente esteja em temperatura amena, o bebê acordado e sem choro, em torno de uma e meia hora após a mamada ${ }^{7}$. Nem sempre, em situação de consulta isto é possível. Porém, podemos obter melhores condições, examinando, primeiramente, a cabeça e o que for possível, sem despir a criança. Ao despi-la, utilizar o princípio da manipulação mínima, conforme orientação de Prechtl: efetuar todas as manobras possíveis de investigação primeiramente com o bebê em decúbito dorsal, depois puxando-o para sentar-se; em seguida, erguendo-o ereto com apoio plantar no plano de exame; segue-se efetuando a manobra da suspensão ventral e, por fim, examinando-o em decúbito ventral ${ }^{7}$.

A seguir, descrevemos a semiologia normal da criança, desde o período neonatal até 7 anos de idade. Para os dois primeiros anos de vida, no caso de avaliação de crianças prematuras, deve ser considerada a idade concepcional. Para tanto, foi convencionado subtrair da idade cronológica o número de semanas correspondentes à diferença entre 40 semanas e a idade gestacional ao nascimento ${ }^{16}$. (Por exemplo, um bebê nascido as 28 semanas de idade gestacional, aos seis meses de idade cronológica, deverá apresentar semiologia neurológica correspondente aos 3 meses).

\section{AVALIAÇÃO DO CONTACTO COM O MEIO}

A fixação do olhar na mãe, enquanto mama é tão precoce no RN quanto a sua capacidade de sucção efetiva, em torno de 32 semanas concepcionais 17. A expectativa em relação ao exame, quantidade de movimento e reação emocional às manobras do examinador devem ser observadas. O choro espontâneo deve ser vinculado às necessidades fisiológicas e, durante o exame, provocado por desconforto ou manobras, como aquelas para desencadear o reflexo de Moro. Aos 2 meses, inicia-se o sorriso social, motivado e, dos 3 aos 6 meses a lalação, expressa por sons guturais, inicialmente, e balbucio de vogais, com amplos movimentos labiais, aos estímulos da mãe ou do examinador $^{18}$. Até o final do primeiro ano, o bebê elabora dissílabos com significado (MAMA, PAPA) e, até 18 meses expressa palavras-frase (ÁGUA=DA ÁGUA). Até 24 meses, constrói frases agramaticais (DÁ AGUA,
NENÊ QUÉ BOLA) e, aos 3 anos introduz pronomes e preposições nas frases. Aos 3 anos, introduz o pronome EU ${ }^{5}$, importante passo na distinção "eu-outro". A linguagem compreensiva precede a expressiva, e, no primeiro ano, desde os primeiros contactos com o meio o bebê demonstra isto, quando reage, negativa ou positivamente, aos estímulos. Efetua tarefas simples por imitação sob comando, no final do primeiro ano ${ }^{19}$.

Deve-se observar que o bebê não se mantém estático, pelo contrário, mostra uma riqueza de movimentos, com variações posturais espontâneas, propiciando-nos excelente oportunidade de exame da qualidade, quantidade e simetria dos movimentos.

\section{EXAME DO SEGUIMENTO CEFÁLICO}

(Ainda com o bebê vestido, no colo da mãe). Inspeção e medidas do crânio: A medida do perímetro craniano se faz com uma fita métrica, passando-a pelo occipício e eminência frontal. A avaliação do perímetro deve levar em conta a estatura. Diz-se macrocefalia ou microcefalia quando o perímetro craniano se encontra acima ou abaixo de dois desvios padrões da média esperada para a estatura observada, respectivamente. Quanto ao formato, de acordo com Diament, a relação entre a distância biauricular (de uma inserção superior da orelha à outra) e anteroposterior (glabela-occipício) é igual a um. Diz-se braquicéfalo, quando a medida biauricular é maior que a anterior e dolicocéfalo ou escafocéfalo, quando a medida biauricular é menor do que a anteroposterior, dando ao crânio um formato de quilha de navio. Estas formas podem ou não estar associadas ao fechamento precoce patológico de suturas (coronárias no caso de braquicefalia e sagital na escafocefalia). A trigonocefalia é sempre consequiência de fechamento precoce patológico da sutura metópica.

A fontanela anterior, ou bregmática, em forma de losango, tem em média ao nascimento dois $\mathrm{cm}$, no sentido coronal e $3 \mathrm{~cm}$, no sagital. Até os nove meses, $50 \%$, e, até um ano e meio $100 \%$ das crianças não mais a apresenta ${ }^{20}$. A fontanela posterior ou lombdoide, triangular, está presente em $40 \%$ dos bebês a termo ao nascimento, mas não ultrapassa um centímetro em sua maior extensão ${ }^{21}$, e o seu fechamento ocorre no primeiro mês. As suturas cranianas podem estar, levemente, sobrepostas ou separadas, dependendo do estado de hidratação, no RN pré-termo. Dado ao fato de o crescimento craniano ser mais acentuado no 
pré-termo, no período entre 28 e 35 semanas, chegando a dois centímetros semanais ${ }^{17}$, as suturas podem também estar separadas alguns milímetros, neste período. No RN a termo, acavalgamento de suturas pode ocorrer na primeira semana, pós-nascimento, em função do amoldamento da cabeça no canal do parto. Após este período, as suturas devem estar justapostas.

Os nervos cranianos, como os medulares, no período do termo, estão mielinizados. Entretanto, as vias que os conectam ao tronco e córtex cerebral ou entre si estão, ainda, em fase variável de amadurecimento $^{22}$. Assim, por exemplo, o fascículo longitudinal medial, um dos responsáveis pelo movimento conjugado ocular, bem como as vias ópticas completam sua mielinização em torno do sexto mês, pós-termo. Isto implica em que nos primeiros seis meses, ocasionalmente, surpreende-se o bebê com movimentos desconjugados, mais comumente com desvio medial de um dos olhos.

As funções dos nervos cranianos podem ser examinadas ${ }^{23}$ :

I - Olfatório: Sabe-se que todas as funções sensoriais iniciam sua mielinização no período fetal e estão amadurecidas no primeiro semestre, pós-natal. Na prática, é possível pesquisar o olfato, após o quarto ou quinto ano de idade, quando a criança pode fornecer informação fidedigna. Pesquisa-se em cada narina, isoladamente. Utilizam-se estímulos, como café e piche, não irritantes da mucosa nasal, pois os irritantes estimulam as terminações sensitivas do trigêmeo e não o olfatório.

II - Óptico: Exame do fundo de olho com oftalmoscópio: A papila ou disco óptico no RN é de coloração mais clara do que a do adulto. A distribuição e morfologia dos vasos, bem como a mácula e restante da retina apresentam-se semelhantes aos do adulto.

Reflexo (R.) de piscamento: II nervo (Óptico) aferente e VII (Facial) eferente. Incidindo-se um foco luminoso nos olhos do bebê, desde o pré-termo viável, estando os olhos abertos ou fechados, em sono ou vigília, há fechamento imediato das pálpebras. Este é um reflexo de defesa que não desaparece com a idade; entretanto, com a maturação e adaptação à luz, a intensidade do estímulo luminoso deve ser maior para se obter o reflexo. Brazelton ${ }^{24} \mathrm{o}$ utiliza para pesquisar a reatividade do neonato.

II e III - Parassimpático: Inspeção do tamanho das pupilas, que devem ser iguais. Pupilas midriáticas (dilatadas bilateralmente) podem ocorrer, por exem- plo, por efeito de drogas simpatomiméticas, como a cocaína, por excitação das vias simpáticas como em hipóxia, ou por herniação do uncus, comprimindo a porção parassimpática do III nervo; pupilas mióticas (constricção), por efeito de drogas depressoras do sistema nervoso, como morfina, benzodiazepínicos e barbitúricos. R. fotomotor e consensual: Incidindo-se a luz de uma lanterna, obliquamente, sobre uma pupila. Há constricção pupilar do mesmo lado estimulado (fotomotor) e, indiretamente, do outro (consensual). R. de acomodação e convergência: A acomodação só é possível observar com a ajuda da criança. A fixação de um objeto distante (infinito) produz midríase, e, fixação do objeto próximo, miose. A convergência pode ser pesquisada, desde que o bebê esteja fixando bem o objeto. A aproximação do objeto na linha média, forçando a convergência ocular, ocasiona miose bilateral.

III - Oculomotor, IV - Patético ou Troclear, VI - Abducente: Responsáveis pelos movimentos oculares. III motor: Estando o globo ocular em posição de olhar para frente, este nervo é responsável pela adução, movimento para cima e para baixo, e pela elevação da pálpebra superior (inerva os músculos retos mediais, superiores e inferiores, oblíquos inferiores e elevadores das pálpebras). IV: Estando o globo ocular aduzido, este nervo promove o movimento para baixo. (inerva os músculos oblíquos superiores). VI: Estando o globo ocular em posição olhando para frente, este é responsável pela lateralização do olho (inerva os músculos retos laterais).

A pesquisa da motricidade extrínseca ocular deve ser realizada, primeiramente, à simples inspeção e, a seguir, enquanto se pesquisa a percepção visual, utilizando-se como estímulo visual um foco luminoso largo, de luz fosca ou um cubo 4 x $4 \mathrm{~cm}$ de cor verme1 ha ${ }^{24}$, a fita métrica ou a face humana, do examinador ${ }^{17}$, por exemplo. A orientação à luz está presente a partir das 34 semanas de idade gestacional ${ }^{8}$. A fixação no foco luminoso é breve no pré-termo. No período do termo, o bebê acompanha brevemente a luz no sentido horizontal. Até o $3^{\circ}$ mês, segue no sentido vertical e em círculo ${ }^{23}$.

V - Trigêmeo: Pode ser testada a sensibilidade da face, através de estímulo tátil, com algodão, ou doloroso, com leve toque da ponta produzida em uma espátula de madeira (agulha não deve ser utilizada porquê fere a pele do bebê). Observa-se a reatividade do bebê. Alguns reflexos que podem ser examinados 
na face (trigêmeo aferente e facial (VII) eferente): R. córneo-palpebral: Ao estimular uma das córneas com um filete de algodão há resposta imediata com fechamento das pálpebras bilateral e, simetricamente. Este reflexo não desaparece, assim como o glabelar. Reflexo glabelar: Percutindo-se com o dedo do examinador (um leve toque) na glabela ocorre fechamento imediato das pálpebras, simétrica e bilateralmente. R. orbicular dos lábios: Percutindo-se a porção média do lábio superior, no filttrum, ocorre contração da musculatura orbicular dos lábios. Este não é obrigatório no RN, e, se presente, costuma ser hipoativo. $\mathrm{O}$ mesmo ocorre com o R. Mentoniano, que tem aferência e eferência pelo $\mathrm{V}$ nervo (trigêmeo, divisão mandibular): R. mentoniano: Percutindo-se o mento, estando a boca levemente aberta, ocorre movimento de contração reflexa do músculo masseteriano. A porção motora do $\mathrm{V}$ nervo craniano pode ser examinada, inspecionando-se e palpando-se a textura dos masseteres, um dos responsáveis pelos movimentos mastigatórios. Deve-se observar a simetria à oclusão dos maxilares, através da justaposição dos dentes incisivos superiores e inferiores. Em lesão motora do trigêmeo, a boca mantém-se aberta e desviada para o lado lesado.

VII - Facial: Este nervo é responsável pela motricidade facial gustação dos $2 / 3$ anteriores da língua, salivação parotídea e lacrimação. Podemos observar a expressão facial do bebê quando este chora ou sorri, reforçando o sulco nasogeniano; quando acompanha um objeto com os olhos, elevando os supercílios e, também, durante o piscamento. Observando-se o bebê dormindo, o fechamento incompleto das pálpebras (uni ou bilateralmente) pode ser sinal de comprometimento periférico do nervo facial. A função gustativa pode ser avaliada com gotas de limão, sal ou açúcar. Está presente, precocemente, no bebê. A função lacrimal pode ser avaliada pelo teste do papel de filtro colocado sobre o conduto lacrimal. A lacrimação com choro é observada até 10 dias após o nascimento a termo. Nas lesões centrais do nervo facial, apenas o andar inferior da face é acometido (apagamento do sulco nasogeniano). Nas lesões periféricas, as porções superiores, incluindo o olho, e inferior são comprometidas.

VIII - Acústico e Vestibular: A audição deve ser testada desde o dia do nascimento, pois é condição para o desenvolvimento da linguagem. Ao ouvir o som de uma campainha, ou de um gongo, ou chocalho (o instrumento-estímulo não está padronizado) o bebê modifica o padrão respiratório, fica "atento", ou modi- fica o movimento corporal, denunciando ter recebido o som. Até o final do primeiro mês, $100 \%$ dos bebês se voltam em direção ao som. Até o sexto mês, localiza o som à altura e abaixo dos ouvidos, estando sentados, e até treze meses, acima da cabeça. Segundo Northern e Downs, $1989^{25}$ dos 7 aos 9 meses a criança localiza fonte de 30 a $40 \mathrm{~dB}$ para o lado e, indiretamente, para baixo. A porção vestibular é testada nas provas de equilíbrio. R. de "olhos de boneca": Ao se desviar a cabeça para um dos lados, há desvio conjugado dos olhos para o lado oposto. Este é um reflexo normal no indivíduo, indicando integridade das vias vestibulo-oculares. Entretanto, estando o indivíduo em vigília, o mesmo é substituído ou inibido pelo sinergismo óculocefalógiro, isto é, ao se desviar a cabeça os olhos acompanham o movimento, fixando os objetos à sua frente. Diament ${ }^{12} \mathrm{o}$ obteve até o final do segundo mês em $\mathrm{RN}$ a termo.

IX - Glossofaríngeo e X -Vago: Observandose a deglutição, mobilidade do pálato e a voz, podemos avaliar as funções motoras destes nervos, a gustação, reflexos do vômito e estornutatório, as funções autonômicas. A elevação do palato posterior pode ser avaliada, solicitando-se ao paciente para, com a cavidade oral bem aberta, emitir a vogal "A" ou se isto não for possível, observar o palato do bebê, quando este estiver chorando. Nas lesões do ramo laringeo superior do vago ocorrem as alterações variáveis na tonalidade da voz. A gustação do $1 / 3$ posterior da língua, somente, deve ser investigada quando a criança pode fornecer informações confiáveis, por volta dos 5 anos. $\mathrm{O}$ R. do vômito pode ser examinado com uma espátula, estimulando-se a faringe posterior. O R. estornutatório ( o V nervo é aferente e a eferência é complexa, participando o X, V, VII, IX nervos torácicos superiores e vias simpáticas) é obtido roçando-se um filete de algodão na mucosa nasal.

XI - Acessório: Responsável pela tonicidade dos músculos esternocleidomastoideo e trapézios, estes devem ser cuidadosamente inspecionados e palpados, observando-se simetria no trofismo e tono. Em caso de lesão unilateral, há inclinação da cabeça e rebaixamento do nível do ombro (estando a criança sentada) para o lado da lesão.

XII - Hipoglosso: Responsável pela motricidade da língua, esta deve ser examinada quanto ao trofismo, motilidade, força muscular e centralização da linha média. Em lesão unilateral, em repouso, dentro da boca a língua está desviada para o lado oposto ao da lesão. Ao exteriorizá-la há desvio para o mesmo lado da lesão. 
Ainda examinando a face, através dos reflexos próprios do $\mathrm{RN}$, podemos verificar alguns dos nervos cranianos:

R. de sucção - Nervos V, VII, XII: A sucção pode ser testada com o dedo mínimo enluvado, do examinador, ou utilizando-se o dorso da mão do próprio bebê. A resposta está presente, reflexa, até 7 meses ${ }^{12}$ no RN ocorrem, normalmente, 12 sucções em 10 segundos 7 .

$R$. da voracidade ou pontos cardeais - $V$ aferente e VII eferente: Estimulando-se com um roçar do dedo do examinador a comissura labial e porção média perilabial superior ( $3^{\circ}$ tempo) e inferior $\left(4^{\circ}\right.$ tempo) há desvio dos lábios para o lado estimulado ${ }^{4}$. Ocorre em $100 \%$ dos RN a termo e desaparece do $3^{\circ}$ ao $6^{\circ}$ mês ${ }^{17}$. As respostas às estimulações laterais estão presentes desde 28 semanas.

$R$. de endireitamento ( $R$. de integração vestibular - tônico - postural): Estando o bebê em decúbito dorsal, ao lateralizar, passiva ou ativamente, a cabeça ocorre lateralização do tronco e pelve para o mesmo lado. Este reflexo não é obrigatório no RN. Entretanto, segundo Mcgraw ${ }^{26,27}$, a mudança de decúbito dorsal para lateral observada a partir do quarto mês é inicialmente reflexa, com as mesmas bases do controle tônico da cabeça sobre os seguimentos corporais.

\section{BEBÊ EM DECÚBITO DORSAL - DESPIDO}

Reflexos Fásicos Apendiculares - Todos os reflexos devem ser obtidos, são exaltados em decorrência da imaturidade da via piramidal, e tornamse normoativos até o final do segundo ano. Neste período, a presença de clono de pés esgotável é normal, desde que simétrico.

R. de Moro - Aferência proprioceptiva cervical, acústica ou vestibular e eferência principal em $\mathbf{C}_{5}-\mathbf{C}_{6}$ : Pode ser desencadeado por um som súbito, ou puxando-se o bebê pelos punhos, a partir da posição em decúbito dorsal e, em seguida, soltando-o, ou com a manobra mais sensível, segundo André Thomas": Toma-se no colo o bebê, como se fosse para acalantálo, porém distanciando-o para que seus membros superiores fiquem livres para abduzirem. Com a mão esquerda, o examinador apóia-lhe o dorso e, com a direita, o occipício. Em seguida, solta-se o apoio do occipício, deixando a cabeça cair alguns centímetros, apoiando-a novamente. Há abdução dos membros superiores e abertura das mãos que estão presentes desde 32 semanas gestacionais e, em 100\%, dos RN a termo ${ }^{17}$. A adução pode faltar. O R. de Moro ${ }^{2}$ vai se fragmentando e desaparecendo até o sexto mês.

R. Preensão palmar - Aferência e eferência raízes C6, C7, C8: O estímulo pode ser o dedo mínimo do examinador. O bebê com 28 semanas concepcionais apenas flete os dedos, progressivamente transmite a força muscular ao longo da mão, punho (32 semanas), antebraço e bíceps braquial (a termo) ${ }^{17}$. No sexto mês, $100 \%$ dos lactentes passam da fase de preensão palmar reflexa para voluntária ${ }^{12}$.

R. Tônico-cervical de Magnus e de Kleijn ou Tônico-cervical Assimétrico ( RTCMK ou RTCA, postural): Rodando a cabeça para um dos lados, ocorre abdução e flexão do membro superior do lado occipital e abdução e extensão do membro superior do lado facial (Posição do esgrimista). O RTCMK ou RTCA pode estar ausente ou se apresentar incompleto, fragmentado desde as 28 semanas concepcionais até o terceiro mês pós-termo ${ }^{8,12,17}$. Resposta fragmentada em membros inferiores, acompanhando o movimento dos superiores, também, pode ocorrer.

R. de Preensão plantar - Aferência e eferência em $S_{1}$ : Interpondo-se o dedo mínimo do examinador na base dos artelhos, estes se fletem. Observado precocemente, nas 25 semanas gestacionais ${ }^{17}$, sempre presente no $\mathrm{RN}$ a termo, este reflexo não mais é obtido no final do primeiro ano ${ }^{12}$.

R. Cutâneo-Plantar - S1 aferente e L4 eferente: No sentido artelhos-calcâneo (para que não se desencadeie a preensão plantar), na porção lateral do pé do bebê, a estimulação tátil pode ser realizada, utilizando-se a ponta (unha) do dedo mínimo do examinador. Observa-se extensão do hálux em 100\% dos $\mathrm{RN}$, desde o mais precoce período ${ }^{8,17}$. Pode ocorrer ou não a abertura dos artelhos em leque. A inversão do reflexo, isto é, a resposta em flexão do hálux ocorrerá em $80 \%$ dos lactentes, por volta dos doze me$\operatorname{ses}^{12}$, podendo em alguns casos chegar à metade do segundo ano, sendo bilateral e simétrico, sem clono de pés.

Exame do tono: O tono muscular deve ser examinado em cada segmento, movimentando-se passivamente as articulações, registrando a resistência à flexão e extensão dos membros e medindo-se os ângulos de flexão ou extensão, conforme descritos pela escola francesa ${ }^{28}$. A movimentação passiva dos membros e a palpação muscular são a melhor forma de verificação do tono, embora subjetiva. Aprende-se, através da prática, a reconhecer a hipertonia fisiológica dos membros nos primeiros meses, a hipotonia fi- 
siológica global que se instala a partir do quarto mês e se estende até o final do segundo ano. A medida de ângulos, além de nos fornecer informações sobre o tono, é útil para verificação da idade gestacional ${ }^{9}$. Particularmente úteis são as medidas dos ângulos, de acordo com Amiel-Tison: O ângulo poplíteo no $\mathrm{RN}$ a termo varia de 90 a 120 graus e, no sexto mês, chega a 180 graus. $\mathrm{O}$ dos adutores das coxas, no $\mathrm{RN}$ a termo, mede de 70 a 120 graus, e chega a $150-170$ no sexto mês. O punho-mão, medido na face ulnar, no $\mathrm{RN}$ a termo, varia de 0 a 30 graus e, no decorrer do primeiro ano, vai se ampliando até 70 graus. O punhoombro, de flexão do antebraço, mede zero graus no RN e vai ampliando até 40 graus no final do primeiro ano. O pé-perna, de flexão do pé, varia de zero a 10 graus, no RN a termo, e amplia-se até 60 graus aos 12 meses. O tono do tronco deve ser examinado, através da flexão (decúbito dorsal), extensão (decúbito ventral) e lateralização passivas, testando-se assim a musculatura abdominal e paravertebral. Observam-se a simetria de resposta e a amplitude do movimento ${ }^{17}$. A força nos membros inferiores pode ser obtida, através da manobra de Branco-Lefèvre ${ }^{11}$, mantendo-os pendentes fora do leito, ou da mesa de exame, observando-se quantidade, qualidade e simetria de movimentos.

\section{PUXANDO-SE A CRIANÇA PARA A POSI- ÇÃO SENTADA}

Exame do tono: A manobra de tração ${ }^{4}$ permite verificar o tono cervical. Puxando-se o bebê pelos punhos, da posição em decúbito dorsal para sentada, a cabeça pendente é sinal de hipotonia cervical anterior, que até o final do terceiro mês, no lactente nascido a termo, é fisiológica. Mantendo-se o bebê sentado com apoio nas axilas e deixando-se a cabeça cair para frente, ocorre imediata extensão cervical, demonstrando tonicidade normal no grupo muscular posterior, extensor cervical. No final da primeira semana, 95\% dos RN nascidos a termo apresenta a musculatura cervical posterior normotônica ${ }^{17}$.

R. de encurvamento do tronco - Aferentes e eferentes nervos intercostais: Um estímulo tátil horizontal no trajeto de qualquer das raizes dorsais desencadeia encurvamento do tronco, por contração da musculatura paravertebral. Este reflexo, com o estímulo suave, que se aplica no RN, desaparece em torno do oitavo mês, porém estímulo mais intenso e inesperado pode elicitá-lo em qualquer idade. Reação de
Galant refere-se ao encurvamento lateral do tronco, provocado pelo estímulo tátil aplicado no sentido vertical, paravertebral ${ }^{17}$.

\section{ERGUENDO-SE A CRIANÇA NA VERTI- CAL (EM PÉ)}

Reflexos próprios do RN: R. de sustentação dos membros inferiores e global ( $R$. postural). Com apoio plantar no plano da mesa de exame, o bebê realiza extensão que pode se limitar aos membros inferiores ou se estender ao tronco e região cervical. Precocemente presente no pré-termo, pode, entretanto, faltar, sem significado patológico 4 . Por outro lado, embora haja referências sobre o seu desaparecimento aos quatro meses, sua persistência pode ocorrer em crianças normais confundindo-se com a fase do erguer-se com apoio, voluntária. R. de colocação (placing) ou "da escada" (integração córtico-cerebelar): Segurandose a criança erguida, pelas axilas, ao roçar o dorso do pé sob a borda de uma mesa, imediatamente a mesma coloca o pé sobre a mesa. Deve ser bilateral e está presente em $100 \%$ dos bebês ${ }^{17}$. Não desaparece com a idade. R. de Marcha (R. postural): Presente de forma incompleta no RN pré-termo de 30 semanas ${ }^{8,17}$, atinge sua manifestação máxima nas 37 semanas e desaparece, em 100\% dos casos, no terceiro mês, após o termo ${ }^{12}$.

\section{SUSPENSÃO VENTRAL}

Exame do tono: Erguendo-se o bebê em posição ventral, apoiado no tórax, pode se testar o tono extensor do tronco e cervical. Esta manobra é particularmente útil no primeiro ano de vida e permite diferenciar, por exemplo, hipotonia patológica da hipotonia fisiológica que se observa a partir do quarto mês ${ }^{12}$. A resposta extensora máxima do tronco, cervical e membros constitui o R. de Landau, que ocorre a partir do quarto mês. Este foi chamado R. Landau I por Diament que, também, descreveu o Landau II em que, durante a resposta à pesquisa do Landau $\mathrm{I}$, forçando-se uma flexão da cabeça, há flexão reflexa do tronco e membros. Estes são reflexos tônicos posturais e labirínticos que não desaparecem com a maturação.

\section{DECÚBITO VENTRAL}

Reflexos próprios do RN: R. do Arrastre (R. postural). Ao ser colocado em decúbito ventral, 
o RN imediatamente inicia movimentos de reptação reflexa, com duração de alguns segundos. Este reflexo não está presente em todos os RN. Não foi estudado em pré-termos e se desconhece o período de desaparecimento. Pode ser desencadeado pela manobra de Bauer, promovendo-se com a mão do examinador um apoio plantar com o bebê na mesma posição e exercendo-se leve força, ocorre a propulsão. R de Passagem do Braço ${ }^{17}$ : Estendendo-se os membros superiores do bebê em decúbito ventral, ao longo do corpo, e procedendo-se rotação de sua cabeça para um dos lados, este, imediatamente, realiza abdução e flexão do membro superior em direção à face. Faz-se a rotação da cabeça para um lado e depois para o outro.

Exame do tono: Em decúbito ventral, o bebê pode ser examinado quanto ao tono cervical posterior, abdominal e paravertebral. A reação de fuga à asfixia, descrita por Illingworth, deve-se ao tono normal da musculatura cervical posterior, que permite a extensão da cabeça. O tono abdominal e paravertebral podem ser examinados, através da extensão passiva da coluna vertebral, elevando os membros inferiores da mesa de exame e observando-se a amplitude do movimento.

\section{POSTURA E MARCHA}

A sequiência no desenvolvimento postural obedece sempre à mesma ordem: Primeiro, o bebê firma o pescoço, e em seguida, sucessivamente com e sem apoio, senta-se, ergue-se e anda. Variações culturais no manejo do bebê modificam o período das fases, mas não a sua seqüência.

O controle cervical ocorre primeiro no grupo posterior ou extensor e depois, até o final do terceiro mês, no grupo anterior.

O "sentar com apoio" deve ser observado, pelo menos em duas de suas fases: Uma fase ocorre em torno do sexto mês, quando, colocando-se o bebê sentado, este permanece por algum tempo sem cair para os lados, apoiado nas próprias mãos (colocadas pelo examinador) entre os membros inferiores ${ }^{29}$. Há curvatura da coluna vertebral, com cifose lombar, em decorrência da hipotonia do tronco. Outra fase ocorre por volta do nono mês, quando a criança senta por si mesma, agarrando-se a um suporte ${ }^{29}$.

O "sentar sem apoio", também, deve ser observado pelo menos em duas fases: Uma, em torno do nono mês, quando, colocando-se o bebê sentado, este permanece por algum tempo sem apoio das mãos, mas pode desequilibrar-se para os lados. A coluna está retificada, indicando tono adequado no tronco. Outra fase ocorre até o décimo segundo mês, quando o bebê pode passar sozinho da posição em decúbito dorsal para sentado ${ }^{29}$. Quanto à marcha sem apoio, ocorre até os 12 meses, em 20\% das crianças brasileiras normais ${ }^{7}$. A aquisição da marcha sem apoio, de modo geral tem sido considerada até a idade de 18 meses $^{29}$. Entretanto existem crianças, inclusive na mesma família, que deambulam um pouco mais tarde, no final do segundo ano, sem apresentarem patologia.

Para atingir a fase do sentar-se sem apoio é necessário, além de ter completado a maturação cervical, ter também completado a fase de mudança de decúbito. Até o final do quinto mês, os bebês mudam de decúbito prono para supino e até o final do sétimo mês, de supino para prono ${ }^{29}$. A passagem de supino para prono, com rotação do tronco e apoio lateral da mão fazem parte do movimento para o sentar sem apoio.

Cerca de 12 a $20 \%$ dos bebês não engatinham e cerca de $3 \%$ exibem o engatinhar atípico ${ }^{30}$, ou seja, evoluem bem até o sentar sem apoio, engatinham de nádega, ou de barriga, ou reptando para trás e demoram até 24 meses para andar sem apoio. Esta variação no modo de engatinhar tem sido atribuída a assimetrias no tono global ou hipotonia, com dificuldade do bebê para suportar o próprio peso. Não há estudos completos, até o momento abordando esta hipótese.

A prova do equilíbrio estático, através da capacidade de manter-se em pé sem apoio, com os pés unidos somente é possível a partir dos três anos de idade. Aos três anos, a criança atende ao comando do examinador permanecendo em pé, de pés unidos, por 30 segundos, mas não obedece ao comando de fechar os olhos, o que somente realiza aos quatro anos ${ }^{18}$.

Ao desenvolvimento das estruturas estatocinéticas se vincula o aparecimento dos reflexos de apoio lateral e de precipitação ou pára-quedas ${ }^{31}$. Ambos iniciam seu aparecimento em torno do oitavo mês, pós-nascimento a termo e estão sempre presentes aos 12 meses. O R. de apoio lateral se obtém quando o lactente se senta sozinho. Estando sentado, mãos sobre as coxas, ao ser empurrado para um dos lados, estende o membro superior e apóia-se, lateralmente, com a mão espalmada na mesa de exame. Deve-se proceder da mesma forma no outro lado e verificar simetria de resposta. O R. de precipitação é obtido elevando-se o bebê em suspensão ventral e procedendo rápida inclinação do polo cefálico, em direção à mesa de exame. Há anteposição e extensão dos membros superiores, simetricamente, buscando apoio das mãos sobre a mesa de exame. 
Quando a marcha se torna independente, inicialmente, no segundo ano, apresenta-se com base alargada em decorrência da imaturidade cerebelar. Entretanto não é ebriosa. Logo a criança contorna bem obstáculos e, no terceiro ano, consegue correr ${ }^{19}$. Provas para teste do equilíbrio dinâmico dos três aos sete anos de idade foram descritas por Lefèvre, $1972^{13}$ e são úteis para verificação do grau de maturação ou sinais de comprometimento das vias ligadas ao equilíbrio, coordenação e sensibilidade. Estão descritas no esquema final deste resumo.

\section{COORDENAÇÃO MOTORA}

A preensão palmar passa a ser voluntária, em $100 \%$ das crianças, aos 4 meses $^{12}$. Inicialmente, a preensão é predominantemente ulnar, em seguida medial $\mathrm{e}$, até o final do primeiro ano deve ser em pinça ${ }^{6}$. Apanhar um objeto sem errar o alvo ( Eumetria) amadurece ao longo dos dois primeiros anos. Justificam-se as tentativas e erros ao tentar alcançar a colher $\mathrm{e}$ levá-la à boca. Não se observam, entretanto, tremores. A prova index-nariz é fidedigna a partir dos 4 $\operatorname{anos}^{13,32}$. Até o sétimo ano, é perfeita a eudiadococinesia, ou seja, movimento alterno da mão estendida, em pronação-supinação do antebraço ${ }^{13,32}$. A prova calcanhar-joelho não foi testada em crianças. Aos 7 anos, pode se verificar a prova de coordenação tronco-membros, em que, estando a criança em decúbito dorsal, braços cruzados, senta-se sem apoio e sem elevar o calcanhar ${ }^{13}$.

\section{SENSIBILIDADE E FUNÇÕES CORTI- CAIS SUPERIORES}

Observamos que, no $\mathrm{RN}$ a termo, há resposta à pesquisa de todos os reflexos fásicos, superficiais, e dos 12 pares de nervos cranianos. A sensibilidade superficial termalgésica e tátil grosseira, também, estão em adiantada fase de amadurecimento, podendo-se pesquisá-las, entretanto, apenas qualitativamente, através das reações motoras até os 5 anos de idade, quando a criança começa a fornecer informações mais fidedignas. O mesmo ocorre à investigação da sensibilidade proprioceptiva vibratória, artrocinética e noção de posição seguimentar. Em relação à sensibilidade tátil grosseira, entretanto, pode-se observar sua presença ou ausência através dos reflexos cutâneos: $\mathrm{Na}$ face, os R. córneo-palpebral e o R. dos pontos cardeais testam os ramos oftálmico, o maxilar e man- dibular do trigêmeo, respectivamente. $O \mathbf{R}$. de encurvamento do tronco, já descrito, pode ser provocado ao longo da região paravertebral, testando-se desde os segmentos $T_{4}$ até $L_{1}$. Os $R$. cutâneo-abdominais abrangem $\mathrm{T}_{6}$ a $\mathrm{T}_{12}$, o R. cremastérico, $\mathrm{L}_{1}$ e $\mathrm{L}_{2}$ e o R. anal superficial, $\mathrm{S}_{2}$ a $\mathrm{S}_{5}$. A sensibilidade proprioceptiva inconsciente pode ser avaliada, em parte, através da marcha espontânea, observando-se a forma como a criança apóia os pés no chão ao dar os passos. Funções perceptivas inconscientes, complexas, que envolvem integração das várias modalidades de sensibilidade, vão amadurecer ao longo da primeira década de vida. Assim, por exemplo, a percepção da saliva e sua contenção dentro da cavidade oral, e a consciência de partes do seu próprio corpo, estão maduras em torno de 24 meses.

A coordenação visuomotora é uma das funções corticais superiores, que pode ser avaliada precocemente. No terceiro mês, o bebê olha para as próprias mãos ${ }^{18}$. Logo, inicia movimentos de apanhar a outra mão presente no campo visual, fazendo o mesmo com objetos colocados neste campo ${ }^{18}$. No quinto mês, passa a estender os membros superiores para buscar o objeto próximo ao campo visual, voluntariamente, e o passa de uma para outra mão. Do oitavo ao décimo segundo mês, descobre um objeto que observa ser escondido sob um lenço ${ }^{19}$. A prova lenço-rosto pode ser utilizada no período neonatal, registrando-se o comportamento do bebê $\hat{e}^{24}$ e, em torno do oitavo mês, o lactente exibe movimento de retirada do lenço, colocado pelo examinador sobre o seu rosto ${ }^{12}$.

Enquanto observamos aspectos semiológicos motores e sensitivos bem definidos da fase sensóriomotora, neste período estão se desenvolvendo, também, as funções corticais superiores, como as praxias e gnosias, resultantes de integração das diversas áreas corticais, e a tríade atenção-memória-evocação, que envolve estruturas como córtex e formações reticulares de tronco e tálamo. As interligações intracorticais amadurecem além deste período, chegando a duas ou três décadas de vida ${ }^{22}$. Praxia significa "fluência na sequiência" de movimentos para uma finalidade, como abotoar, amarrar sapatos, falar, assoprar uma vela, assoviar, escrever. Quanto a praxia de mãos, aos 4 anos a criança é capaz de abotoar e aos 7 anos dar laço no sapato ${ }^{19}$. Aos 5 anos, em torno de $50 \%$ das crianças, realiza movimentos como abrir uma das mãos e fechar a outra alternadamente, como também unir, seqüencialmente, o polegar aos demais dedos ${ }^{32}$. As idades para os movimentos bucofonatórios, como 
assoprar, chupar no canudinho, bem como os mais complexos como exteriorizar a língua e colocá-la para cima, ou entre o lábio inferior e gengiva, não estão bem estabelecidas. A praxia de fala, ou seja, a capacidade de seqüenciação das sílabas nas palavras, sem hesitações, depende do amadurecimento da zona pre-motora da linguagem e suas conexões, o que ocorre em torno dos 2 anos, quando a criança emite palavras e constrói frases agramaticais. Gagueira fisiológica pode ocorrer em torno de três anos de idade.

Gnosia significa "reconhecimento" e, portanto, está ligada às vias de recepção auditiva, visual ou tátil discriminativa. A gnosia auditiva pode ser testada pelo reconhecimento de ritmos, sons e, no hemisfério dominante para a fala, a gnosia verbal, ou seja, o reconhecimento dos sons da fala. A gnosia visual pode ser testada através de "discriminação" de formas como bandeiras (colocam-se duas iguais entre outras para serem encontradas) para a idade de 5 anos, ou para idade acima de 8 anos os testes propostos por Luria ${ }^{33}$. Gnosia tátil pode ser testada através do reconhecimento de formas pelo tato (estereognosia), a partir dos 4 $\operatorname{anos}^{13}$.

Formas mais complexas de gnosias, que são resultado de integração entre as acima citadas, nos fornecem importantes informações sobre as aquisições corticais superiores, como a integração visuo-espacial e visuomotora que podem ser avaliadas, através do teste de Bender ${ }^{34}$. Todas as formas de gnosia e praxia são importantes para a aquisição de leitura e escrita espontânea ou sob ditado, havendo maturação de áreas específicas envolvidas com símbolos gráficos da língua, independentemente da maturação do reconhecimento e praxia para outros símbolos.

No esquema abaixo, introduzimos itens de semiologia neurológica geral, evolutiva e outros parâmetros do desenvolvimento. Os itens apresentados reúnem propostas dos diversos autores já citados, incluindo Gesell ${ }^{18}$ e dados da Escala de Denver ${ }^{19}$. Estes itens foram escolhidos a partir da informação de que pelo menos $95 \%$ das crianças nascidas a termo ou com idade corrigida devem estar cumprindo estes itens, nas idades consideradas. Assim se torna mais útil a aplicação da mesma nas avaliações onde se busca uma idade limite para a normalidade, a partir da qual se considera atraso.

Na medida do possível, constatamos os dados durante o exame, sem interrogar a mãe sobre os mesmos. Além do material de exame neurológico clássico, os seguintes materiais devem ser utilizados: 8 cubos de $2,5 \mathrm{~cm}$ de lado (para provas de coordenação e praxia); uma caixa de lápis de cera (cores, noção de quantidade, desenhos), passas secas (preensão em pinça), uma bola de tênis (coordenação), cartões com desenhos para cópia: circulo, quadrado, triângulo, cruz, losango (coordenação visuomotora); um carrinho pequeno com fio de um metro (equilíbrio dinâmico), dois fios de lã de tamanhos diferentes (noção de tamanho); dado pequeno, bolinha de gude, moeda, algodão (estereognosia); quadro temático simples (reconhecimento de figuras e descrição).

\section{EXAME NEUROLÓGICO E DO DESENVOL- VIMENTO DA CRIANÇA (Período de 0 a 7 anos)}

\section{Em qualquer idade}

- Devem estar presentes todos os reflexos miotáticos fásicos, esperados para o adulto, bem como a semiologia completa dos 12 pares de nervos cranianos, e sensibilidades, com a ressalva das particularidades, e às vezes impossibilidades técnicas para obtenção dos mesmos, em cada idade.

\section{Até um mês de idade}

- Olha para o rosto das pessoas que o observam.

- Segue na horizontal, com os olhos, a luz de uma lanterna colocada a $30 \mathrm{~cm}$ dos olhos.

- Ao ouvir uma voz chamando-o, reage de algum modo: mudando o ritmo da respiração ou abrindo mais os olhos e demonstrando "atenção ou rodando a cabeça para um dos lados como se quisesse localizar a fonte do som".

- Colocado em DV, levanta a cabeça por alguns segundos.

- Reflexos primitivos obrigatórios desde o nascimento: Sucção, voracidade, preensão palmar, preensão plantar, moro, colocação, encurvamento do tronco, cutâneo plantar em extensão. Reflexos primitivos não obrigatórios: Marcha, RTCMK, sustentação, arrastre, endireitamento.

\section{Três meses}

- Sorri reativamente.

- Olha para as próprias mãos.

- Junta as mãos.

- Ao ouvir uma voz, fica atento.

- Colocado em DV, apoia-se sobre os MMSS fletidos

- Desaparece o R. de marcha e tônico-cervical assimétrico.

\section{Quatro meses}

- Sons guturais ("AN GU”)

- Colocado sentado, a cabeça fica firme.

- Início de preensão palmar voluntária. 


\section{Seis meses}

- Inicia sons vocálicos: "AAAAAA"

- Localiza som (molho de chaves), na altura dos ouvidos.

- Em DV, estende os membros superiores e eleva o tórax.

- Muda decúbito.

- Sentado, o tronco ainda cai para a frente e para os lados.

- Apanha o objeto e passa para outra mão.

- Reflexos primitivos ausentes, exceto o de preensão plantar e cutâneo-plantar em extensão.

\section{Oito meses}

- Alcança, olha, passa para a outra mão, e explora o objeto.

Nove meses

- Lalação: "BAA BAA BAA" "TAA TA TA" MA-MA".

- Localiza som ao lado e acima da cabeça (até 13 meses).

- Sentado, fica sozinho, tronco ereto, sem cair.

- Recusa aproximação de pessoas estranhas.

- Descobre objeto que observa ser escondido ao seu alcance.

\section{Doze meses}

- Lalação: "Mama" "Papa" "Dada"

- Procura o objeto que cai ou rola de suas mãos.

- Preensão usando os dedos polegar e indicador (Pinça).

- Põe-se em pé com apoio.

- Em DV, senta-se sem ajuda

- R. de apoio lateral e pára-quedas.

- R. de preensão plantar ausente.

\section{Dezoito meses}

- Primeiras palavras-frases: "Dá"

- Brinca imitando (telefone no ouvido, tenta rabiscar).

- Aponta para o que quer.

- Torre de 2 cubos.

- Vence obstáculos, abre porta.

- Anda sem ajuda.

- R. Cutâneo-plantar em flexão.

\section{Dois anos}

- Combina 2 palavras

- Associa idéias: aperta o interruptor e olha para a lâmpada. Aponta para a bolsa, por. ex., da mãe e diz "mamãe".

- Imita trabalhos caseiros.

- Retira a roupa.

- Usa a colher.

- Aponta para partes do corpo.
- Aponta para figuras em um livro.

- Faz rabiscos no papel.

- Torre de quatro cubos.

- Chuta um bola.

- Sobe e desce de uma cadeira.

Dois anos e meio

- Nomeia figuras simples.

- Copia traços, sem direção.

- Joga a bola de cima para baixo.

- Sobe escada, colocando os dois pés em cada degrau.

- Corre.

Três anos

- Frases gramaticais.( EU)

- Diz o próprio nome completo.

- Gagueira fisiológica.

- Brinca de faz-de-conta.

- Copia um círculo.

- Copia traço na vertical.

- Torre de 8 cubos. Até $3 a$ e $6 \mathrm{~m}$ faz ponte.

- Anda para trás 3 metros, puxando um carrinho.

- Equilíbrio estático com olhos abertos.

- Pedala triciclos.

- Coloca os sapatos, não faz laço.

\section{Quatro anos}

- Vai sozinho ao vaso sanitário.

- Controle da enurese noturna.

- Frases completas. Ainda troca letras: R por L, S por T; ou suprime as letras (sapato por pato).

- Usa plural.

- Senso de humor, noção de perigo.

- Preensão do lápis igual adulto.

- Copia cruz.

- Noção de "mais comprido".

- Lava as mãos e ajuda no banho.

- Agarra uma bola arremessada.

- Sobe escada alternando os pés.

- Equilíbrio estático com olhos fechados.

Quatro anos e meio

- Compreende frio, cansaço, fome.

- Compreende perto, longe, em cima, em baixo.

- Abotoa a roupa

\section{Cinco anos}

Seis anos

- Copia um quadrado.

- Desenha homem com 6 partes

- Anda para trás colocando um pé atrás do outro (ponta do pé-calcanhar), com olhos abertos, 2 metros.

- Estereognosia. 


\section{Sete anos}

- Noção de hora, dia, mês e ano.

- Fornece o endereço completo.

- Descreve o que vê.

- Copia triângulo e inicia a cópia do losango.

- Amarra o cordão do sapato.

- Reconhece direita e esquerda no próprio corpo.

- Salta e bate duas palmas, antes de tocar os pés no chão.

- Eudiadococinesia.

- Fica parado em pé, por 10 segundos com um pé atrás do outro (ponta de pé-calcanhar).

- Joga bola em uma altura $30 \times 30 \mathrm{~cm}$ e $2 \mathrm{~m}$, fazendo abdução do MS (joga por cima).

- Anda colocando o calcanhar na ponta do outro pé, para frente 2 metros, com olhos abertos.

- Conhece as cores primárias.

- Desenha de memória a figura humana.

- Fica longe da mãe sem protestar.

- Conta histórias, fala sem trocar letras.

- Escolhe amigos.

- Se veste sem ajuda.

FUNAYAMA CAR. Neurologic examination in children. Medicina, Ribeirão Preto, 29: 32-43, jan./mar. 1996

ABSTRACT: The author details the current method of neurologic examination from neonatal period to seven years old, emphasizing maturative features and presenting a scheme that includes data from neurologic examination and developmental diagnosis.

UNITERMS: Child Development. Infant; Newborn. Neurologic Examination. Child

\section{REFERÊNCIAS BIBLIOGRÁFICAS}

1. MAGNUS, R \& DE KLEIJN A Die Abhangigkeit des tonus der extremitenmuskeln von der Kopfstellung Pfliigers. Arch Ger Physiol 145: 455, 1912.

2. MORO E Das erste trimenon. Munch Med Wochenschr 65: 1147, 1918.

3. LANDAU A. Uber einen tonischen lagereflex beim alteren saugling. Klin Wochenschr 2: 1253, 1923.

4. THOMAS A \& DARGASSIES S Etudes neurologiques sur le nouveauné et le jeune nourison. Masson, Paris, 1952.

5. ILLINGHWORTH RS The development of the infant and the young child normal and abnormal. E \& S Livingstore, Edinburgh, London, 1960.

6. SHERIDAN MD The development progress of infants and young children. HMSO, London, 1968.

7. PRECHTL H \& BEINTEMA D The neurological examination of the full-term newborn infant. Heinemann Medical Books, London, 1964.

8. BRANDT I Patterns of early neurological development. In: FALKNER W \& TANNER JM The human growth, 2th ed JM Plenum Press, London, v.3, Cap. 8, p. 469-518, 1986.

9. DUBOWITZ LMS; DUBOWITZ,V \& GOLDBERG C Clinical assesment of gestacional age in the newborn infant. $\mathbf{J}$ Pediatr 77: 1, 1970.
10. CORIAT LF Evolution de las atitudes posturales del lactante. Arch Argent Pediatr 56: 17-27, 1960.

11. LEFÈVRE AB Contribuição para a padronização do exame neurológico do recém-nascido normal. Tese de Livre Docência, Faculdade de Medicina da USP, São Paulo, 1950.

12. DIAMENT AJ Contribuição para a sistematização do exame neurológico de crianças normais no primeiro ano de vida. Tese de Livre Docência, Faculdade de Medicina da USP, São Paulo, 1967.

13. LEFÈVRE AB Exame neurológico evolutivo. Sarvier, São Paulo, 1972.

14. LEFÈVRE BH Neuropsicologia infantil. Sarvier, São Paulo, 1989.

15. GUARDIOLAA; FERNANDEZ LL\& ROTTANT. Um modelo de avaliação das funções corticais. Arq Neuropsiquiatr 47: 159-164, 1989.

16. SIEGEL LS. Correction for prematurity and its consequences for the assesment of the very low birth weight infant. Child Dev 54: 1176-1188,1983

17. DARGASSIES S Desarrollo neurologico del recien nacido de termino y prematuro. Médica Panamericana, Buenos Aires, 1977.

18. GESELL A \& AMATRUDA CS. Development diagnosis. Paul C. Hoeber, New York, 1956.

19. FRANKENBURG WK. Denver developmental screening test. J Pediatr 71: 181-191, 1967. 
20. POPICH G \& SMITH DW. Fontanels: Range of normal size. J Pediatr 80: 749-752, 1972.

21. PAIXÃO AC. Dimensão linear das fontanelas em crianças nascidas de termo e pré-termo, do nascimento aos 12 meses de vida. Tese de Doutoramento. Faculdade de Medicina de Ribeirão Preto da USP, Ribeirão Preto, 1988.

22. YAKOVLEV PI \& LECOURS AR. Myelogenetic cycles. In MINKOWSKI M. A regional development of the brain in early life. Blackwell Scientific Publications, Oxford, 1967.

23. DeJONG, RN. The neurologic examination. 4th ed. Harper \& Row Pubishers, New York, p.83-240, 1979.

24. BRAZELTON TB. Neonatal behavioral assessment scale. Lippincott, Philadelphia, 1973.

25. NORTHERN JL \& DOWNS MP. Audição em crianças. $3^{\mathrm{a}}$ ed. Manole, São Paulo, p. 50, 1989.

26. MCGRAW MB. Neural maturation of the infant as exemplified in the right reflex, or rolling from a dorsal to a prone position. J Pediatr 18: 385-394,1941

27. McGRAW MB. The neuromuscular maturation of the human infant. Columbia University \& Press, New York, 1943.

28. AMIEL-TISONC. Standardizing the physical examination during the first year. Curr Probl Pediatr 7: p. 1-50, 1976.
29. ZDANSKA-BRINKENM. \& WOLLANSKIN A graphic method for the evaluation of motor development in infants. Dev Med Child Neurol 11: 228-241, 1969.

30. ROBSON P. Shuffling, hitching or sliding: some observation in 30 otherwise normal children. Dev Med Child Neurol 12: 608-617, 1970.

31. MILANI-COMPARETTIA\& GIDONE EA. Routine develop-mental examination in normal and retarded children. Dev Med Child Neurol 9: 631-638, 1967.

32. BACHIEGA MCM. Exame neurológico evolutivo da criança normal de 3 a 7 anos de idade. Contribuição para avaliação da fidedignidade das provas. Dissertação de Mestrado. Faculdade de Medicina da USP, São Paulo, 1979.

33. LURIAAR. Higher cortical functions in man. Basic Books, New York, 1966.

34. BENDER L. Test guestaltic visomotor. Paidós, Buenos Aires, 1955.

Recebido para publicação em 04/03/96

Aprovado para publicação em 14/03/96 